\title{
Piroliz Uygulanmış Çeltik Sapları ile Sulu Çözeltilerden Renk Giderimi
}

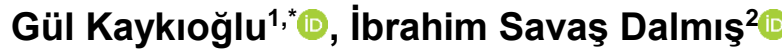 \\ ${ }^{1}$ Tekirdağ Namık Kemal Üniversitesi, Çorlu Mühendislik Fakültesi, Çevre Mühendisliği Bölümü, 59860, Çorlu, Tekirdağ. \\ ${ }^{2}$ Tekirdağ Namık Kemal Üniversitesi, Çorlu Mühendislik Fakültesi, Makina Mühendisliği Bölümü, 59860, Çorlu, Tekirdağ.
}

\section{Özet}

$B u$ çalışmanın amacı, piroliz uygulanmış pirinç sapları ile (PPS) sulu çözeltilerden metilen mavisi (MB) giderim performansını değerlendirmektir. $\mathrm{pH}$ (4, 5.9 (doğal pH), 7, 9 ve 11), başlangıç boya konsantrasyonu (5, 10, 15 ve $20 \mathrm{mg} / \mathrm{L})$ ve temas süresi (0, 1, 5, 15, 30, 60, 90 ve 120 dakika) gibi çeşitli deneysel parametrelerin etkisini değerlendirmek için sabit sicaklikta $\left(20^{\circ} \mathrm{C}\right)$ ve sabit adsorban dozunda $(1 \mathrm{~g} / \mathrm{L})$ kesikli çalışmalar yapılmıștır. Ayrıca; farklı dozlarda (500, 1000, 1500, 2000 ve $2500 \mathrm{mg} / \mathrm{L} \mathrm{NaCl)} \mathrm{tuz} \mathrm{ilavesiyle} \mathrm{iyonik}$ şiddetin boya çözeltisinden renk giderim verimi üzerine etkisi değerlendirilmiştir. Boya çözeltisinin pH değerinin 4'ten 11'e yükseltilmesiyle PPS tarafindan boya tutulumunun bir miktar azaldiğı (qe değerleri için $8.5 \mathrm{mg} / \mathrm{g}$ 'dan yaklaşık $8.2 \mathrm{mg} / \mathrm{g}$ 'a) ve en iyi giderme veriminin doğal pH'ta elde edildiği gözlenmiştir. Bütün deneylerde boya tutulumu hızl olmakta ve artan temas süresi ile birlikte adsorpsiyon artmaktadır. Metilen mavisi giderim verimi artan iyonik şiddet ile birlikte hafif artış göstermiştir. $2000 \mathrm{mg} / \mathrm{L} \mathrm{NaCl}$ uygulamasinda \%91 giderme verimi elde edilirken, $2500 \mathrm{mg} / \mathrm{L} \mathrm{NaCl}$ uygulamasında giderme verimi \% 87'e düsmüstür. PPS ile MB adsorpsiyonunda $R^{2}$ değerleri dikkate alındiğında Freundlich modeline göre Langmuir modelinin daha uyumlu olduğu belirlenmiştir. MB boyarmaddesi için PPS adsorbanının maksimum adsorpsiyon kapasitesi $12.5 \mathrm{mg} / \mathrm{g}$ 'dır. PPS için deneysel kinetik veriler yalancı birinci derece modele uyumludur $\left(R^{2}=0.9952\right)$.

\section{Anahtar Sözcükler}

Pirinç Sap1, Piroliz, Adsorpsiyon, Metilen Mavisi, Renk Giderimi

\section{Color Removal from Aqueous Solution with Pyrolysis-Treated Rice Straw}

\begin{abstract}
The objective of this study is to evaluate the performance of pyrolysis-treated rice straw (PPS) in the removal of methylene blue (MB) from aqueous solution. Batch studies were performed to evaluate the influences of various experimental parameters like $\mathrm{pH}(4,5.9$ (natural $\mathrm{pH}), 7,9$ and 11), initial dye concentration $(5,10,15$, and $20 \mathrm{mg} / \mathrm{L})$, and contact time $(0,1,5,15,30,60,90$, and $120 \mathrm{~min})$ at constant temperature $\left(20^{\circ} \mathrm{C}\right)$ and adsorbent dose $(1 \mathrm{~g} / \mathrm{L})$. Also; the effect of ionic strength with the salt addition at different doses $(500$, $1000,1500,2000$, and $2500 \mathrm{mg} / \mathrm{L} \mathrm{NaCl}$ ) was evaluated on the color removal efficiency from the dye solution. It was observed that the dye uptake by PPS was slightly decrease (from $8.5 \mathrm{mg} / \mathrm{g}$ to about $8.2 \mathrm{mg} / \mathrm{g}$ for qe values) when the $\mathrm{pH}$ of dye solution was increased from 4 to 11 and the best removal efficiency was obtained at the natural pH (5.9). Uptakes of dye were rapid and the adsorption increased with increasing contact time in all experiments. Methylene Blue removal efficiency increased slightly with increasing ionic strength. While the removal efficiency was $91 \%$ at $2000 \mathrm{mg} / \mathrm{L} \mathrm{NaCl}$ application, decreased to $87 \%$ at $2500 \mathrm{mg} / \mathrm{L} \mathrm{NaCl}$. According to the $R^{2}$ values for the adsorption of MB on PPS, Langmuir model yields fit better than the Freundlich model. The maximum adsorption capacity of PPS adsorbent for $M B$ dye was $12.5 \mathrm{mg} / \mathrm{g}$. The kinetic experimental data fitted the pseudo-first-order model for PPS $\left(R^{2}=0.9952\right)$.
\end{abstract}

Keywords

Rice Straw, Pyrolysis, Adsorption, Methylene Blue, Color Removal

\section{Giriş}

Boyarmaddeler birçok endüstride, özellikle tekstil endüstrisinde kullanılmaktadır. Tekstil atık suyu yoğun renktedir ve bu atık suların doğrudan alıcı ortama deşarjı, ışı geçirgenliğinin azalması, estetik bozulma, su ortamındaki yaşamın olumsuz etkileri gibi birçok çevre problemine neden olabilir. Tekstil atık suyunun arıtılması için geleneksel yöntemler çoğunlukla organik karbon uzaklaştırmasına dayanır. Bununla birlikte, bu arıtma sistemleri biyolojik parazitlere ve oksidasyona karşı direnç gösteren boyarmadde içeren atık sudan renk gideriminde etkili değildir. Pıhtılaşma-flokülasyon, ileri oksidasyon işlemleri $\left(\mathrm{H}_{2} \mathrm{O}_{2}+\mathrm{Fe}^{+2}\right.$ olarak), membran işlemleri ve elektrokimyasal yöntemler renk gideriminde etkilidir. Ancak, bu yöntemlerin yüksek maliyet ve yüksek miktarda çamur oluşumu gibi dezavantajları vardır (Kaykığlu ve Gunes 2016). 
Renk giderimi için en çok tercih edilen yöntem adsorpsiyondur ve genellikle adsorban olarak aktif karbon kullanır (ElHalwany 2010). Bu, aktif karbonun kolay uygulanabilir ve etkili olması ile ilgilidir (Panneerselvam vd. 2011; Salehia vd. 2010). Bununla birlikte, aktif karbonun maliyeti, adsorpsiyon işleminin renk gideriminde kullanımını sınırlayan önemli bir faktördür. Renk gideriminde oldukça başarılı olan adsorpsiyon işlemi için aktif karbona alternatif farklı adsorbanlara sahip olma kavramı yıllardır ilgi çekmektedir. Bu nedenle adsorpsiyon çalışmaları çeşitli doğal ve sentetik tipte adsorbanlarla yapılmıştır. Bazı araştırmacılar, tarımsal artıkların, yüksek adsorpsiyon kapasitesine sahip aktif karbon üretimi için hammadde olarak kullanımını araştırmıștır. Aktif karbon üretimi için zeytin çekirdeği, çay yaprağı, hindistan cevizi ve badem kabukları, muz kabukları, portakal kabukları, findık kabukları, pirinç kabukları ve şeker kamışı başarıyla kullanılmıştır. Tarımsal kalıntılardan aktif karbon üretiminin hem çevresel hem de ekonomik faydalar sağladığı birçok araştırmada vurgulanmıştır (Kalderis vd. 2008; Naiya vd. 2009; Foo ve Hameed 2009).

Genellikle aktif karbon üretimi için oksijensiz ortamda $800^{\circ} \mathrm{C}^{\prime}$ nin altında inert gaz akışı eşliğinde $\left(\mathrm{N}_{2}\right.$ gibi) oksijensiz yakma ile materyalin karbonizasyonu ve aktifleştirme işlemi uygulanmaktadır. Karbonizasyon işlemi ile karbonik olmayan elementler uçucu gazlara dönüşerek uzaklaşmaktadır. Kalan karbon atomlarının oluşturduğu yapı düzensizdir. $\mathrm{Bu}$ sayede aralarında boşluklar oluşmaktadır. Bu boşluklar sayesinde iyi adsorban özellikler gösterebilmektedir. Karbonize edilmiş materyalin adsorpsiyon verimine etkisini gösteren kalite parametrelerini, piroliz uygulamasındaki ısıtma hızı, son sıcaklığı, son sıcaklıkta bekletme süresi ve ham maddenin yapısı ve fiziksel özellikleri etkilemektedir (Çaylak 2007).

Türkiye'de çeltik üretimi (özellikle Marmara ve Karadeniz bölgelerinde) 100.000 hektarlık ekili alanda yapılmaktadır (Elekçioğlu ve Tülek 2009). Çeltik tarlalarında hasattan sonra kalan çeltik sapları çeltiklerin hazırlanmasını zorlaştıran en önemli faktördür. Tarlada kalan sap miktarı yaklaşık 350 kg/da'dır (Sürek vd. 2007). Pirinç sapları, toprağa karışma maliyetinin yüksek olması ve yüksek kül içeriğinden (\% 18-20) dolayı ayrışma zorluğu sebebiyle yasalar tarafından yasaklanmalarına rağmen yakılmaktadır. Ancak, çeltik saplarının yakılması, topraktaki azot, fosfor $(\approx \% 25)$, potasyum $(\approx \%$ 20) ve kükürt (\% 5-60) gibi maddelerin kaybolmasına, hava kirliliği ve yangın tehlikesi gibi olumsuz etkilere neden olabilir (Akçay 2014).

Biyokömür (biochar) sınırlı oksijen uygulaması altında biokütlenin pirolizinden üretilen karbon ürünüdür. Son yıllarda çeşitli adsorpsiyon uygulamaları için düşük maliyetli adsorban üretiminde kullanılmaktadır. Biyokömür üretiminde Hindistan cevizi kabuğu, kayısı çekirdeği, mısır koçanı gibi tarımsal atıklar besleme materyali olarak kullanılmıştır (Demiral ve Çemrek Kul 2014; Zhang vd. 2016; Suman ve Gautam 2017).

Günümüzde, sucul alıcı ortamlardaki renk kirliliği nedeniyle akuatik hayatın olumsuz etkilenmesi ve estetik bozulmanın endişe verici boyutlara gelmesi, hem de Su Kirliliği Kontrolü Yönetmeliği ve Yerüstü Su Kalitesi Yönetmeliğine eklenen renk parametresi sebebiyle atıksulardan rengin giderilmesi konusundaki çalışmalara ağırlık verilmektedir. Saman (Hameed ve El-Khaiary 2008; Xu vd. 2011) ve bambu (Yang vd. 2013) kullanılarak elde edilen biyokömürün su ve atıksulardan renk giderimi üzerine çalışmalar yürütülmüştür. Xu vd. (2011) çalışmalarında fıstık kabuğu, soya fasulyesi kabuğu ve pirinç kabuğuna piroliz uygulanması ile elde edilen biyokömürler ile sulu çözeltiden metil violet boyarmaddesinin giderilmesi üzerine çalışmışlardır. Elde edilen adsorpsiyon kapasiteleri sırasıyla, 256, 179 ve $124 \mathrm{mg} / \mathrm{g}$ olarak belirlenmiştir.

Bu çalışmanın amacı, Trakya bölgesinde önemli miktarlarda oluşan pirinç saplarının hem ekolojik hem de ekonomik olarak değerlendirilmesi ile, atıksulardan rengin gideriminde kullanılan aktif karbona alternatif yaratabilmektir. Çalışmada, piroliz işlemine tabi tutulmuş pirinç saplarından üretilen adsorban (PPS) kullanılarak metilen mavisi (MB) boyarmaddesi ile hazırlanan sulu çözeltilerden rengin adsorpsiyonu değerlendirilmiştir.

\section{Materyal ve Metot}

\subsection{Adsorbanın Hazırlanması}

Bu çalışmada piroliz ünitesi için besleme olarak kullanılan çeltik sapı; çeltik üretiminin yoğun olarak gerçekleştirildiği Edirne ilinin İpsala ilçesinden toplanmıştır. Çeltik sap örnekleri peletleme işlemine tabi tutulmadan önce bıçaklı tip laboratuvar değirmeni kullanılarak 40 mesh büyüklüğüne parçalanmıştır. Peletlenen çeltik sapları 2 saat süreyle $600{ }^{\circ} \mathrm{C}$ 'de azot gazı ile birlikte piroliz işlemine tabi tutulmuştur (Aktaş vd. 2017).

Piroliz prosesi, aşağı akışlı, sabit yataklı ve boğazsız tipte bir piroliz ünitesinde gerçekleştirilmiştir. Piroliz reaktörünün çapı $170 \mathrm{~mm}$ ve boyu $750 \mathrm{~mm}$ olup, reaktörün efektif yüksekliği 700 mm'dir. Piroliz ünitesi, hız1 $200 \mathrm{~kg} / \mathrm{m}^{2} \mathrm{~h}$ olacak şekilde işletilmiştir (Aktaş vd. 2017).

\subsection{Analizler}

Adsorbanlar FEI Quanta FEG 250 model taramalı elektron mikroskobu (SEM) kullanılarak incelenmiştir. Bu inceleme düşük vakum modunda (20-80 Pascals) düşük vakum detektörü (LFD) ile bir ön hazırlık yapılmadan incelenmiştir. Adsorpsiyon işleminden sonra toplanan numunelerde boya konsantrasyonu, Thermospectronic AquaMate marka spektrometre kullanılarak maksimum absorbansa $(\lambda \max 670 \mathrm{~nm})$ karşı1ık gelen bir dalga boyunda ölçüldü. 


\subsection{Boyarmadde adsorpsiyonu}

Metilen mavisi (MB) katyonik bir boya olup, tekstil ve kağıt endüstrisinde bol miktarda kullanım alanına sahiptir (ElHalwany 2010). Adsorbat olarak kullanılan MB, Merck marka olarak temin edilmiştir. $50 \mathrm{mg} / \mathrm{L}$ 'lik stok çözelti hazırlanarak adsorpsiyon çalışmaları için seyreltmeler $(5-20 \mathrm{mg} / \mathrm{L})$ yapılarak kullanılmıştır. Çalışmada kullanılan boyarmadde olan MB'nun kimyasal formülü Şekil 1'de gösterilmiştir. Adsorpsiyon çalışmaları metilen mavisi boyarmaddesi ile farklı konsantrasyonlarda hazırlanan $(5,10,15$ ve $20 \mathrm{mg} / \mathrm{L})$ sentetik çözeltiden, farklı pH şartlarında (4, 5.9, 7, 9 ve 11) ve sabit adsroban dozunda (1 g/L) gerçekleştirilmiştir. Adsorpsiyon çalışması sırasında numune alma sıklığı 0, 1, 5, 15, 30, 60, 90 ve 120 dakika şeklinde olmuş ve her numune alımından sonra $0.1 \mathrm{~N} \mathrm{HCl}$ ve $0.1 \mathrm{~N} \mathrm{NaOH}$ ile $\mathrm{pH}$ ayarlaması yapılmıştır. Toplanan numuneler 3500 devir/dakika ile 5 dakika süresince santrifüj işlemine tabi tutulmuş, daha sonra renk ölçümü spektrofotometrede gerçekleştirilmiştir.

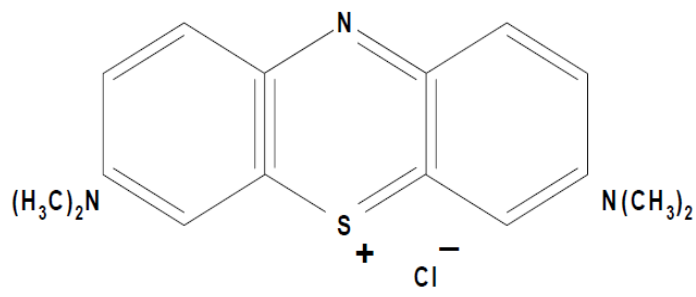

Şekil 1: Metilen mavisi boyar maddesinin kimyasal formülü

\subsection{Adsorpsiyon İzotermleri}

Eşitlik (1) kullanılarak denge durumunda adsorpsiyon kapasitesi hesaplanmıştır.

$$
q e=\left(\mathrm{Co}_{\mathrm{o}}-\mathrm{Ce}\right) \mathrm{V} / \mathrm{m}
$$

Bu eşitlikte, denge durumunda birim PPS'nin adsorpladı̆̆ı MB miktarı (mg/g) qe, adsorpsiyondan önce (başlangıçta) çözeltideki MB konsantrasyonu (mg/L) $\mathrm{C}_{0}$, denge durumunda çözeltide kalan MB konsantrasyonu (mg/L) Ce, çözeltinin hacmi (L) V ve PPS dozu (g) $m$ ile ifade edilmektedir.

Adsorplama işlemi, PPS yüzeyinde tutulan MB konsantrasyonu ve çözeltide kalan MB konsantrasyonu arasında denge oluşuncaya kadar devam etmektedir. Denge durumu adsorpsiyon izotermleri ile ifade edilebilmektedir. Bunun için, Freundlich, Langmuir, R-P, Temkin, ve D-R gibi çeşitli izoterm modeller kullanılmaktadır (Kaykığlu ve Güneş 2016). Adsorpsiyon prosesinin tasarımını en uygun şekilde yapabilmek amacıyla denge eğrileri için uygun korelasyonun bulmak gerekmektedir. Langmuir ve Freundlich izotermlerine ait lineerize edilmiş denklemler Tablo 1'de verilmiştir.

Tablo 1: Langmuir ve Freundlich izotermleri

\begin{tabular}{|l|l|l|}
\hline Langmuir & $\frac{C e}{q e}=\frac{1}{q \max . K_{L}}+\frac{C e}{q \max }$ & $\begin{array}{l}K_{L}(\mathrm{~L} / \mathrm{g}) \text { denge sabiti, } \\
\begin{array}{l}\max (\mathrm{mg} / \mathrm{g}) \text { maksimum adsorpsiyon kapasitesi } \\
\text { Freundlich }\end{array}\end{array}$ \\
\hline Inqe $=\operatorname{In} K_{F}+\frac{1}{n F} \operatorname{InCe}$ & $\begin{array}{c}K_{F}(\mathrm{~L} / \mathrm{g}) \text { adsorpsiyon kapasitesi, } \\
1 / n F \text { adsorpsiyon yoğunluğu }\end{array}$ \\
\hline
\end{tabular}

Langmuir izotermi, adsorban yüzeyinin enerji bakımından benzer olduğu varsayımına dayanmaktadır. Tek tabakalı homojen adsorpsiyonu açıklamak için kullanılmaktadır (El-Halwany 2010).

Freundlich izotermi adsorban yüzeyindeki adsorpsiyon yoğunluğunu belirlemek için kullanılır (El-Halwany 2010). Deneysel sonuçlar için çizilen grafikler ile Tablo 1'de belirtilen denklemler kullanılarak qmax, $\mathrm{K}_{\mathrm{L}}, 1 / \mathrm{nF}$ ve KF değerleri hesaplanmıştır (Kaykığlu ve Güneş 2016). 


\subsection{Adsorpsiyon Kinetikleri}

Sorpsiyon hızının belirlenmesi adsorpsiyonun veriminin değerlendirilmesinde önemlidir (Ayoob vd. 2008; Huang vd. 2007). Bu sebeple, PPS kullanılarak MB'sinin sulu çözeltilerden gideriminin kinetik açıdan değerlendirilmesi yapılmıştır. Kinetik değerlendirme için, birinci derece kinetik ve ikinci derece kinetik modelleri kullanılmışıtır (Tablo 2).

Tablo 2: Adsorpsiyon kinetik modelleri

\begin{tabular}{|l|c|l|}
\hline Birinci derece kinetik model & $\operatorname{In}\left(q_{e}-q_{t}\right)=\operatorname{In} q_{e}-k_{1} t$ & $k_{1}\left(\mathrm{dak}^{-1}\right)$ \\
\hline İkinci derece kinetik model & $\frac{t}{q_{t}}=\frac{1}{k_{2} q_{e}^{2}}+\frac{t}{q_{e}}$ & $k_{2}\left(\mathrm{~g} \mathrm{mg}^{-1} \mathrm{dak}^{-1}\right)$ \\
\hline
\end{tabular}

Lagergren eşitliği, yalancı birinci derece kinetikleri için en çok kullanılan eşitliklerden olup, sıvı faz sistemlerde adsorpsiyon hızının belirlenmesinde kullanılmaktadır (Gupta ve Bhattacharyya 2011). Adsorpsiyon işleminin birinci derece kinetik modele uyumlu olup olmadığı $t$ 'ye karşı $\log (q e-q t)$ grafiği çizilerek elde edilen doğrudan belirlenebilmektedir (Aydın vd. 2008). Çizilen grafik yardımıyla $q e$ ve $k_{1}$ değerleri de hesaplanmaktadır. qe, denge durumundaki, $q t, \mathrm{t}$ süresinde adsorplanan MB miktarların $1(\mathrm{mg} / \mathrm{g})$ ifade etmektedir. İkinci derece kinetik modelde t'ye karşı t/qt grafiği çizilmekte ve $q e$ ve $k_{2}$ değerleri grafiğin eğiminden ve kesim noktasından belirlenebilmektedir.

\section{Sonuçlar}

\subsection{Adsorbanların karakteristikleri}

Deneysel çalışmalarda kullanılan adsorbanın EDAX analizi sonucunda elde edilen kimyasal içeriklerine ait \%'lik dağılımlar şu şekildedir; $78.83 \mathrm{C}, 9.07 \mathrm{O}, 1.35 \mathrm{Na}, 0.60 \mathrm{Mg}, 9.08 \mathrm{Si}, 0.29 \mathrm{P}$ ve $0.77 \mathrm{Cl}$. Buna göre, adsorpsiyonda etkili olan C ve Si içeriklerinin sırasıyla \% 78.83 ve \%9.08 gibi yüksek değerlerde olduğu görülmektedir. SEM görüntüleri Şekil 2 'de gösterilmiştir. SEM görüntülerine göre, hazırlanmış olan adsorbanın yüzeyinde boyarmadde adsorpsiyonunda etkili olabilecek mikron boyutunda çok sayıda gözeneğin bulunduğu görülmektedir (Claoston vd. 2014).

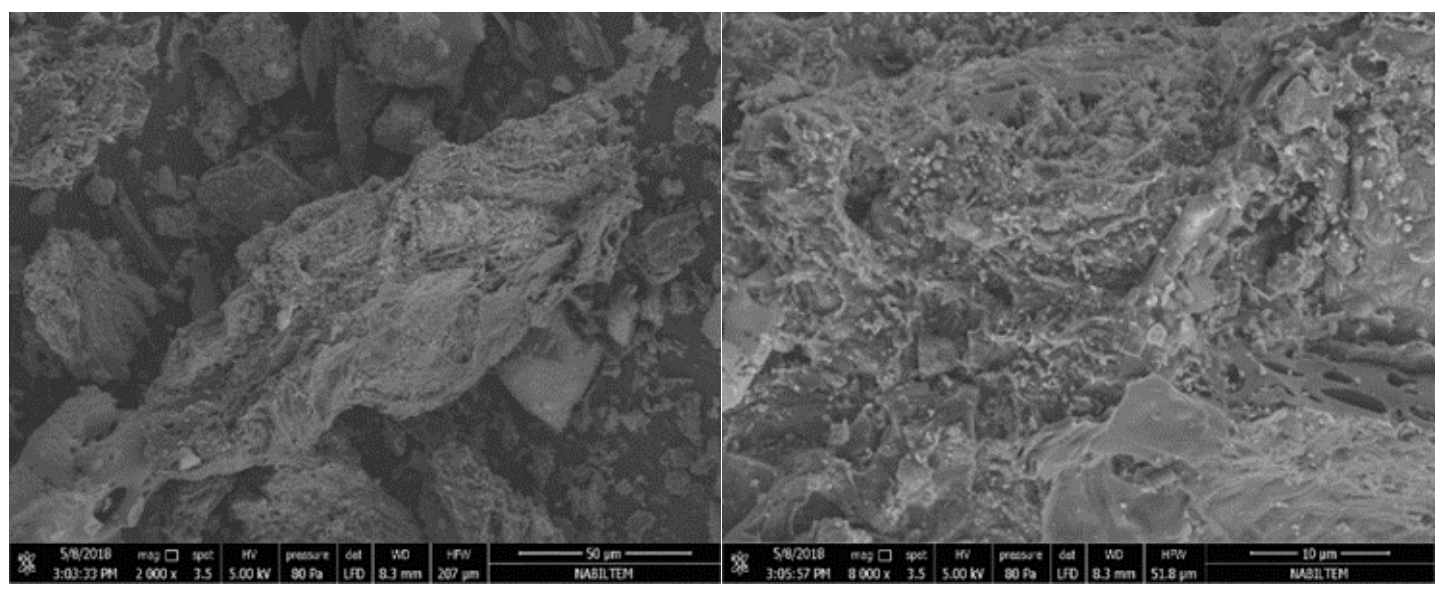

Şekil 2: Adsorbana ait SEM görüntüleri (2000X ve 8000X)

\section{$3.2 \mathrm{pH}$, temas süresi ve başlangıç boya konsantrasyonunun etkisi}

Adsorpsiyonda sulu çözeltinin pH'1, adsorbanların yüzey yüklerini değiştirmesi dolayısıyla, adsorpsiyon kapasitelerini etkileyen önemli bir parametredir. PPS için pH değişimine bağlı olarak qe değerleri Şekil 3 'te gösterilmiştir. 


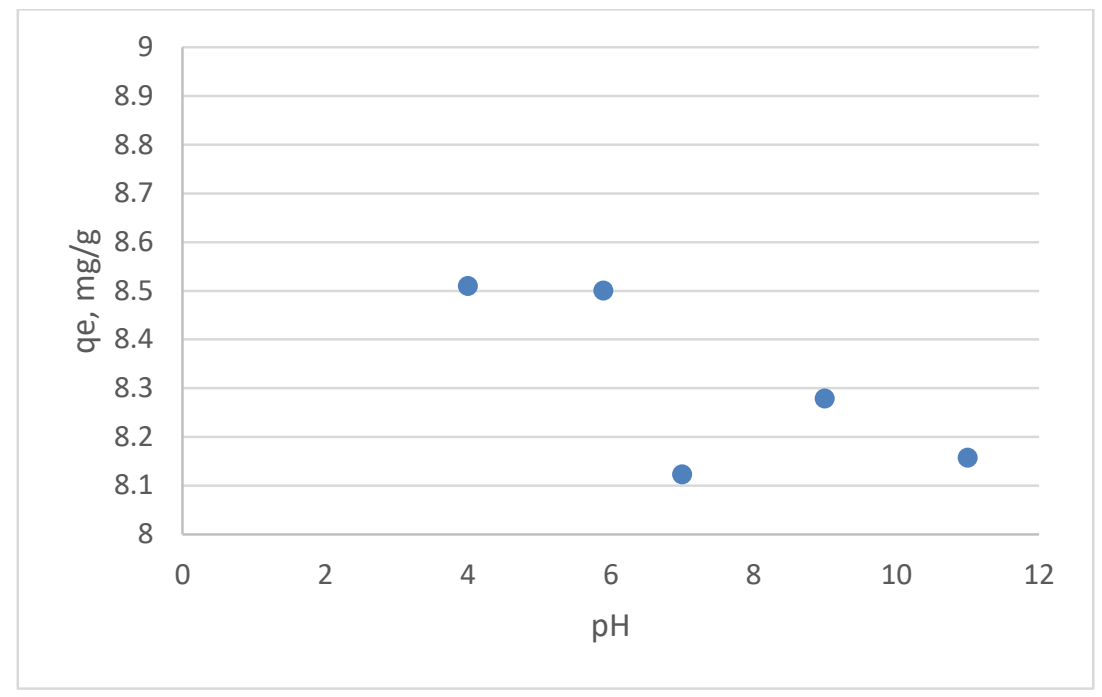

Şekil 3: pH'ın etkisi qe üzerine etkisi (Co=10 mg/L, 1g/L adsorban dozu)

PPS ile MB adsorpsiyonunda pH etkisi 4, 5.9 (orjinal pH), 7, 9 ve 11 için değerlendirilmiştir (sabit $\mathrm{C}_{0}=10 \mathrm{mg} / \mathrm{L}$ ve 1 $\mathrm{g} / \mathrm{L}$ adsorban dozu). Çözeltinin $\mathrm{pH}$ değerindeki artışla birlikte, $\mathrm{pH}$ 7'den itibaren qe değeri çok hafif bir azalış göstermiş ve pH 4 ve pH 5.9'da elde edilen qt değerleri eşit olarak $(8,5 \mathrm{mg} / \mathrm{g})$ belirlenmiştir. MB'nun katyonik bir boya olması sebebiyle adsorpsiyon mekanizmasında elektrostatik çekimden ziyade, iyon değişiminin etkili olabileceği ifade edilebilmektedir. İyon değişiminde, MB PPS’nin gözeneklerine doğru hareket etmekte olup, PPS porlarının içerisine doğru difüzyon hızlı olmaktadır. Gözenek kanallarının çapı küçüldükçe difüzyon yavaşlamaktadır (Naiya vd. 2009). Maksimum qe değerleri pH 5.9'da (orjinal pH) elde edilmiştir. Daha sonraki değerlendirmelerde pH 5.9 değeri referans olarak alınacaktır.

$10 \mathrm{mg} / \mathrm{L}$ başlangıç boya konsantrasyonu, $1 \mathrm{~g} / \mathrm{L}$ adsorban dozu ve sabit $\mathrm{pH}$ şartlarında PPS ile yapılan MB adsorpsiyonu çalışmasında 120 dakikalık temas süresinde giderme verimleri Şekil 4’te gösterilmiştir.

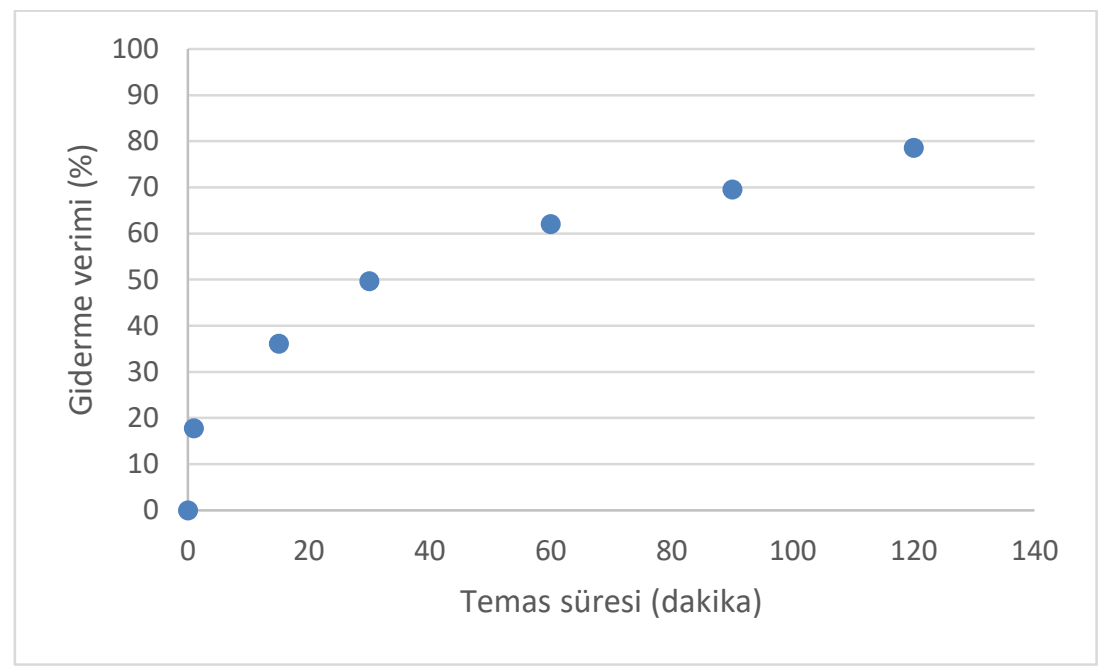

Şekil 4: PPS ile boyarmadde adsorpsiyonunda temas süresinin etkisi

Şekil 4'e göre, adsorpsiyon hızlı olup, temas süresindeki artış ile giderme verimi artış göstermiştir. 120 dakikada denge durumuna ulaştığı kabul edilmiştir. PPS kullanılarak MB gideriminde farklı Co'ların etkisi Şekil 5 ve Şekil 6'da gösterilmiştir. 


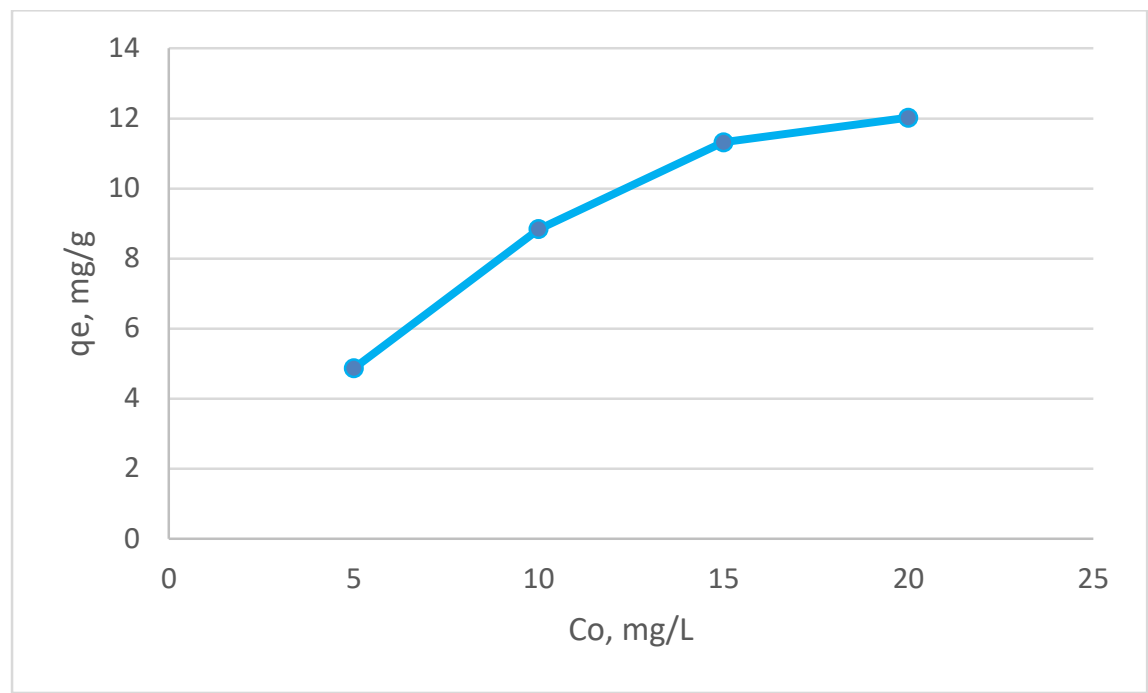

Şekil 5: PPS ile boyarmadde adsorpsiyonunda başlangıç boya konsantrasyonun qe'ye etkisi

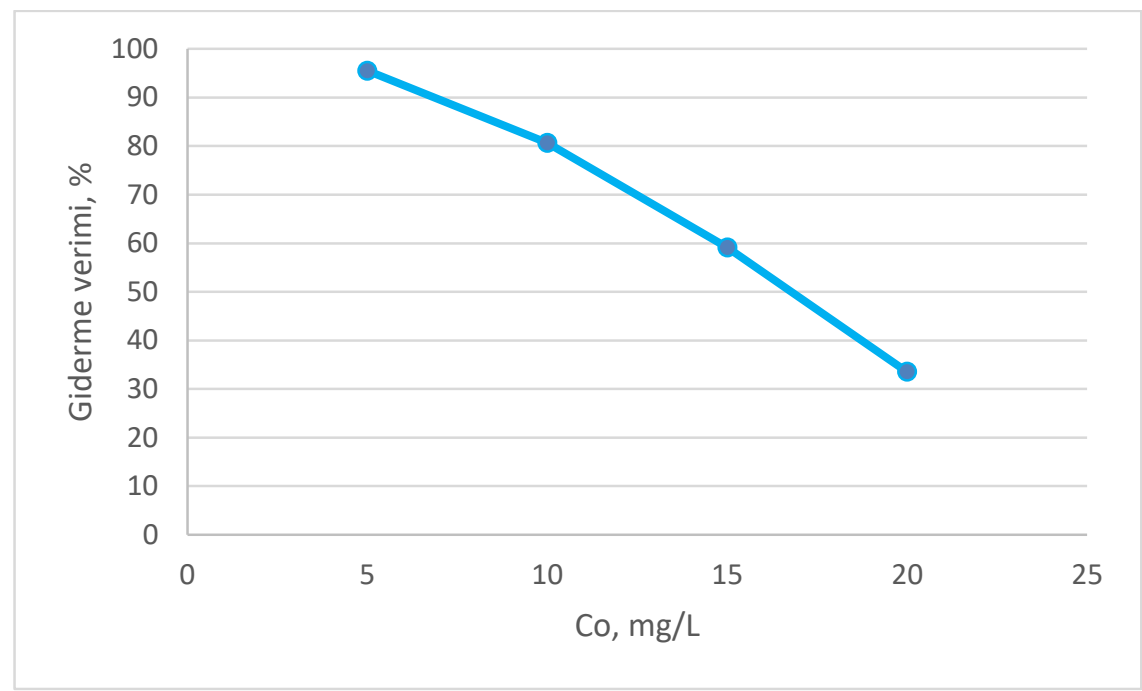

Şekil 6: PPS ile boyarmadde adsorpsiyonunda başlangıç boya konsantrasyonun giderme verimine etkisi

MB adsorpsiyonunda elde edilen qe değerleri, artan MB konsantrasyonuna bağlı olarak artış göstermişken, giderme verimleri düşmüştür. $5 \mathrm{mg} / \mathrm{L} \mathrm{MB}$ için elde edilen qe değeri $4.86 \mathrm{mg} / \mathrm{g}$ iken $20 \mathrm{mg} / \mathrm{L}$ MB konsantrasyonunda qe değeri $12.023 \mathrm{mg} / \mathrm{g}$ olarak belirlenmiştir. Giderme verimleri başlangıç MB konsantrasyonundaki artışa bağlı olarak azalmıştır. $5 \mathrm{mg} / \mathrm{L} \mathrm{MB}$ için elde edilen giderme verimi \%95.48 iken, $20 \mathrm{mg} / \mathrm{L} \mathrm{MB}$ konsantrasyonu için elde edilen giderme verimi \%33.52'ye düşmüştür. Bu durum, MB'nin kütle transferi direncinin üzerinde gerekli olan itici gücün başlangıç $\mathrm{MB}$ konsantrasyonu ile sağlanması şeklinde ifade edilebilmektedir (Mane vd. 2007). Co'da artış olması ile birlikte, PPS yüzeyindeki bağlayıcı alanların MB tarafından dolması ile giderme verimi azalmıştır. Düşük Co değerlerinde, MB PPS yüzeyindeki etkili bölgelerde bağlanabilmekte olup, yüksek adsorpsiyon oranı elde edilebilmiştir. MB konsantrasyonundaki artış ile birlikte PPS yüzeyinde adsorbe edilebilecek alanlar azalmaktadır (Naiya vd. 2009; Dinçer vd. 2007).

\subsection{Adsorpsiyon izotermleri}

Bu çalışmada elde edilen verilere Langmuir ve Freundlich izotermleri uygulanmış olup, izoterm eğrileri Şekil 7'de gösterilmektedir. Tablo 3'te ise izotermler için belirlenen katsayı değerleri ve regresyon katsayıları $\left(\mathrm{R}^{2}\right)$ verilmiştir. PPS kullanılarak MB'nin adsorpsiyonu için $\mathrm{R}^{2}$ değerlerine göre Langmuir modeline daha fazla uyum gösterdiği görülmektedir. PPS için $\mathrm{R}^{2}$ değerleri Langmuir ve Freundlich için sırasıyla 0.999 ve 0.9749 olarak belirlenmiştir. Langmuir modeline göre gerçekleşen adsorpsiyon, tek tabakalı, sınırlı ve uniform adsorpsiyon alanlarını temel almaktadır. PPS'nin MB boyarmaddesi için maksimum adsorpsiyon kapasitesi (qmax) $12.5 \mathrm{mg} / \mathrm{g}$ 'dır. 
Tablo 3: Langmuir ve Freundlich izotermleri için sabit değerler

\begin{tabular}{|c|c|c|c|c|c|}
\hline \multicolumn{3}{|c|}{ Langmuir } & \multicolumn{3}{c|}{ Freundlich } \\
\hline qmax & $\mathrm{K}_{\mathrm{L}}$ & $\mathrm{R}^{2}$ & $\mathrm{~K}_{\mathrm{F}}$ & $1 / \mathrm{n}$ & $\mathrm{R}^{2}$ \\
\hline 12.5 & 1.72 & 0.999 & 7.121 & 0.23 & 0.9749 \\
\hline
\end{tabular}
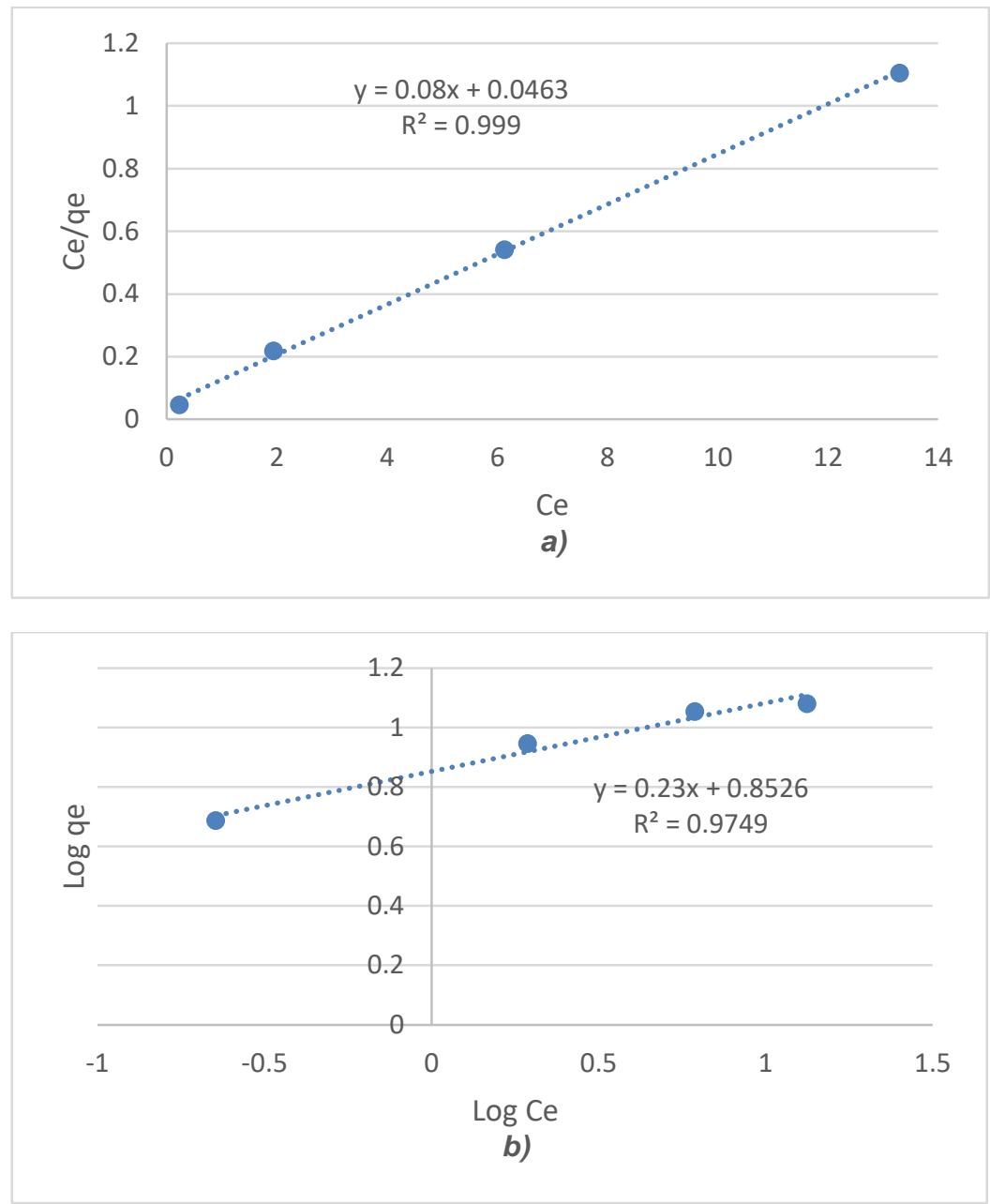

Şekil 7: PPS için izoterm eğrileri ( $\mathrm{pH}=5.9, t=120$ dak, Co = 5, 10, 15, $20 \mathrm{mg} / \mathrm{L}, \mathrm{m}=1 \mathrm{~g} / \mathrm{L})$ a) Langmuir, b) Freundlich

McKay vd. (1989), Langmuir modelini daha iyi açıklayabilmek için $R_{L}$ boyutsuz ayırma faktörünü belirlemişler ve hesaplanması için eşitlik (2)'yi kullanmışlardır.

$$
R_{L}=\frac{1}{1+K_{L} \cdot C_{o}}
$$

$\mathrm{R}_{\mathrm{L}}$ 'nin 0-1 arasında olması uyumlu adsorpsiyonu ifade etmektedir. Bu çalışmada elde edilen $\mathrm{R}_{\mathrm{L}}$ değerleri 0 ile 1 arasında belirlenerek, PPS MB adsorpsiyonu için uyumludur. Freundlich izotermine göre, 1/n heterojenite faktörüdür. PPS yüzeyinin heterojenliği arttıkça, 1/n değeri sıfıra yaklaşmaktadır. 1/n değerinin 1'den küçük olması durumu, PPS'nin MB giderimi için uygunluğunu ifade etmektedir (Mane vd. 2007; Jain vd. 2009). Tablo 4'te PPS için MB'nun adsorpsiyonuna ait $1 / \mathrm{n}$ değeri 0.23 olarak verilmiştir. MB'nin adsorpsiyon yöntemiyle giderimi konusunda yapılmış önceki bazı çalışmalar ve elde edilen qmax değerleri Tablo 4 'te verilmiştir. 
Tablo 4: MB adsorpsiyonu ile ilgili yapılan çalışmalarda elde edilen qmax değerleri

\begin{tabular}{|c|c|c|}
\hline Kullanılan adsorban & $\begin{array}{c}\text { qmax } \\
(\mathbf{m g} / \mathbf{g})\end{array}$ & Kaynak \\
\hline $\begin{array}{c}\mathrm{H}_{2} \mathrm{SO}_{4} \text { ile aktifleştirilmiş pirinç kabuğu külü (300 } \\
{ }^{\circ} \mathrm{C}^{\prime} \text { de yanmış) }\end{array}$ & 44.25 & Kaykığlu ve Güneş 2016 \\
\hline $\begin{array}{c}\mathrm{H}_{2} \mathrm{SO}_{4} \text { ile aktifleştirilmiş pirinç kabuğu külü (550 } \\
{ }^{\circ} \mathrm{C}^{\prime} \text { de yanmış) }\end{array}$ & 32.68 & Kaykığlu ve Güneş 2016 \\
\hline Granül aktif karbon & 12.21 & Kayk1oğlu ve Güneş 2016 \\
\hline Graphene oksit/ kalsiyım alijinat kompoziti & 181.81 & Li vd. 2013 \\
\hline Sepiolite & 57.28 & Auta ve Hameed, 2012 \\
\hline Aktif karbon & 263.49 & Li vd. 2013 \\
\hline Zeytin çekirdeği & 22.0 & Alaya vd. 1999 \\
\hline Findık kabuğu & 8.82 & Aygun vd. 2003 \\
\hline Kolemanit atığ1 & 25.77 & Kayk1oğlu 2016 \\
\hline Üleksit atığ1 & 47.62 & Kayk1oğlu 2016 \\
\hline Piroliz olmuş pirinç sap1 & 12.5 & Bu çalışma \\
\hline
\end{tabular}

PPS’nin adsorpsiyon kapasitesi, diğer adsorbanların adsorpsiyon kapasitesi ile karşılaştırıldığında yüksek adsorpsiyon kapasitesi ortaya koyamadığı görülebilmektedir. Li vd. (2003) tarafindan yapılan çalışmada ticari aktif karbon kullanılarak MB giderimi gerçekleştirilmiştir. Bu çalışmada elde edilen qmax değeri $263.49 \mathrm{mg} / \mathrm{g}$ olarak belirlenmiştir. Bu değer çalışmamızda elde etmiş olduğumuz qmax değerinden yaklaşık 20 kat daha büyüktür. Bu durum, aynı oranda giderme verimi elde edilmesi için ticari aktif karbona oranla 20 kat daha fazla PPS kullanılması gerektiğini ortaya koymaktadır. Ancak, Kaykığlu ve Güneş (2016) tarafından yapılan çalışmada granül aktif karbonun MB adsorpsiyonunda elde edilen qmax değeri çalışmamızda elde edilen qmax değeri ile yaklaşık eşit bulunmuştur. PPS'ye uygulanabilecek çeşitli kimyasal aktivasyon yöntemleri ile qmax değerleri arttırılabilmekte olup, bu konuda daha fazla çalışma yapmaya gereksinim duyulmaktadır. Ticari aktif karbonun yerine kullanılacak PPS'nin bir atık materyalden elde edilmiş olması ekonomik ve ekolojik açıdan uygulamayı avantajlı hale getirmektedir.

\subsection{Adsorpsiyon Kinetikleri}

Adsorpsiyon çalışmalarında adsorpsiyon hızının belirlenmesi önemlidir (Dahri vd. 2014). Adsorpsiyon hızının belirlenmesinde, birinci derece ve ikinci derece kinetik modelleri kullanılmıştır. PPS ile MB adsorpsiyonunda kinetik modelin belirlenmesi için elde edilen grafikler ve kinetik parametreler Şekil 8 ve Tablo 5 'te verilmektedir.

Kinetik çalışmaları sonucunda elde edilen $\mathrm{R}^{2}$ değerlerine göre, $\mathrm{Co}=10 \mathrm{mg} / \mathrm{L}$ ve $1 \mathrm{~g} / \mathrm{L}$ adsorban dozunda PPS'nin birinci derece kinetik modeline uyumlu olduğu belirlenmiştir. Yüksek boyarmadde konsantrasyonlarında sürücü kuvvette artış yaratması sebebiyle, adsorpsiyon hızı artmaktadır (Hameed vd. 2008). PPS için hesaplanan denge adsorpsiyon kapasiteleri ( $q e$, hes), deneysel adsorpsiyon kapasiteleri (qe, den) ile uyumlu bulunmuştur.

Tablo 5: PPS ile MB adsorpsiyonu için kinetik parametreler $\left(C_{0}=10 \mathrm{mg} / \mathrm{L}, \mathrm{m}=1 \mathrm{~g} / \mathrm{L}, \mathrm{pH}=5.9\right)$

\begin{tabular}{|c|c|c|c|c|}
\hline \multicolumn{5}{|c|}{ Birinci derece } \\
\hline Co & qe, den $(\mathrm{mg} / \mathrm{g})$ & qe, hes $(\mathrm{mg} / \mathrm{g})$ & $\mathrm{k}_{1}\left(\mathrm{dak}^{-1}\right)$ & $\mathrm{R}^{2}$ \\
\hline $10 \mathrm{mg} / \mathrm{L}$ & 8.501 & 6.049 & 0.02303 & 0.9952 \\
\hline \multicolumn{5}{|c|}{ İkinci derece } \\
\hline Co & qe, den $(\mathrm{mg} / \mathrm{g})$ & qe, hes $(\mathrm{g} / \mathrm{mg}$ dak $)$ & $\mathrm{k}_{2}(\mathrm{~g} / \mathrm{mg}$ dak $)$ & $\mathrm{R}^{2}$ \\
\hline $10 \mathrm{mg} / \mathrm{L}$ & 8.501 & 9.017 & 0.0086 & 0.9824 \\
\hline
\end{tabular}



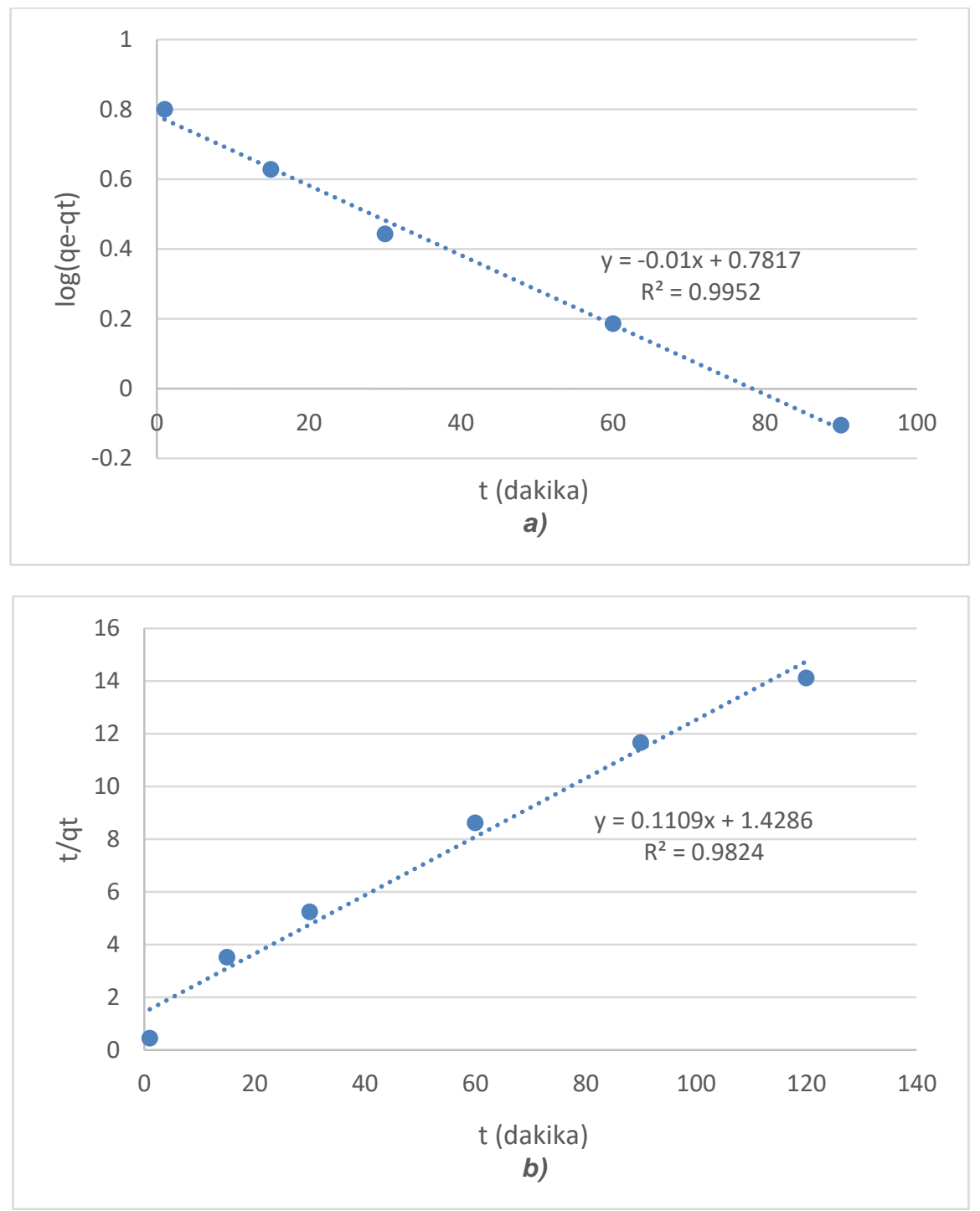

Şekil 8: PPS'ye ait kinetik model grafikleri ( $\mathrm{pH} 5.9,10 \mathrm{mg} / \mathrm{L} \mathrm{MB)}$ a) birinci derece b) ikinci derece

\subsection{Iyonik şiddetin etkisi}

PPS ile boyarmadde adsorpsiyonunda iyonik şiddetin etkisi, boyarmadde çözeltisinin içerisine 500, 1000, 1500, 2000 ve $2500 \mathrm{mg} / \mathrm{L} \mathrm{NaCl}$ ilave edilerek gerçekleş̧irilmiştir. Elde edilen giderme verimleri Şekil 9'da gösterilmiştir. Buna göre, iyonik şiddetteki artış ile birlikte $\mathrm{MB}$ giderme verimlerinde artış görülmüştür. $500 \mathrm{mg} / \mathrm{L} \mathrm{NaCl}$ olması durumunda maksimum giderme verimi $\% 92$ gibi yüksek seviyelere ulaşmış iken, hiç $\mathrm{NaCl}$ olmaması durumunda maksimum giderme verimi \%78.6'dır. $2000 \mathrm{mg} / \mathrm{L} \mathrm{NaCl}$ uygulamasında \%91'lik maksimum giderme verimi elde edilmiş, ancak $2500 \mathrm{mg} / \mathrm{L}$ $\mathrm{NaCl}$ uygulaması ile maksimum giderme verimi bir miktar düşmüştür (\%87).

Endüstriyel atıksularda boyarmaddelerin yanında yüksek konsantrasyonlarda tuz da bulunabilmekte olup, tuz konsantrasyonu adsorpsiyonu etkileyebilmektedir. Tipik boyama proseslerinde tuz boya adsorpsiyonunu hızlandırdığı gibi yavaşlatabilmektedir. Çeşitli çalışmalarda boyar madde adsorpsiyonu sırasında tuz konsantrasyonunun etkisi değerlendirilmiştir (Mouni vd. 2018; Cheng vd. 2018; Wu vd. 2014). Genel olarak iyonik şiddette artış olması ile birlikte adsorpsiyon kapasitesinde düssme gözlenmektedir. Bunun sebebi adsorban yüzeyi ve adsorplanan madde arasında elektrostatik etkileşim olmasıdır (Mouni vd. 2018). Elektrolit ilavesiyle iyonik şiddetin değişimi, elektrolit iyonlarının adsorpsiyon yüzeyindeki potansiyel ara yüzeyleri etkilemesi ve elektrolit iyonları ve adsorplanan iyonların sorpsiyon alanları için yarışması şeklinde etkileyebilmektedir. Ancak, yapılan çalışmada çözeltide iyonik şiddetin arttırılması ile

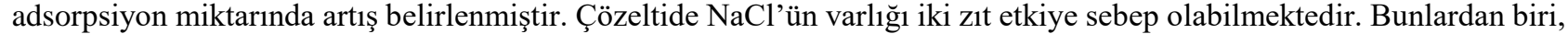
boya molekülleri ve adsorban arasındaki elektrostatik etkileşimi perdeleyebilmesidir. $\mathrm{NaCl}$ konsantrasyonundaki artış ile MB adsorpsiyon kapasitesi azalabilmektedir. Diğeri de, tuzun boya moleküllerinin protonlarına ayrışmasını (dissosiasyonu) kolaylaştırması ile adsorpsiyonu pozitif yönde etkilemesidir. 
Elde edilen sonuçlara göre iyonik şiddetin varlığı ile adsorpsiyon olumlu etkilendiğinden boyar maddenin ayrışmasından ileri geldiği söylenebilmektedir. Yapılan çeşitli boyarmadde adsorpsiyonunda NaCl'ün etkisinin değerlendirildiği bazı çalışmalarda benzer sonuçlar elde edilmiştir (Wang vd. 2010; Wu vd. 2014; Cheng vd. 2018).

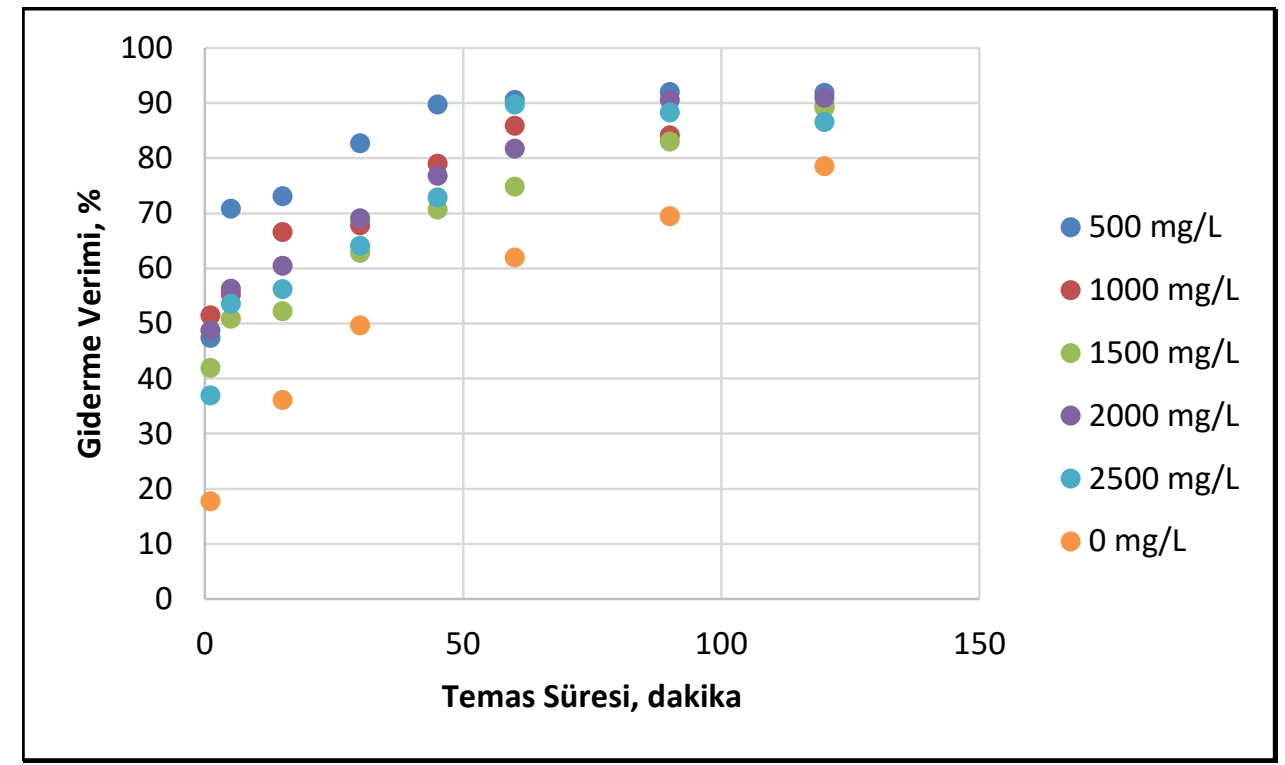

Şekil 9: PPS ile MB boyarmaddesinin adsorpsiyonunda iyonik şiddetin etkisi

\section{Sonuç}

Bu çalışmada metilen mavisinin (MB) adsorpsiyon ile gideriminde tarımsal atık olan pirinç saplarına piroliz uygulanması sonucunda elde edilen adsorban (PPS) kullanılmıştır. Çalışmaya ait sonuçlar aşağıdaki gibi özetlenmiştir;

- Çalışmada kullanılan adsorbanın kimyasal içerik dağılımından, \%78.83 C ve \%9.08 Si'dan oluştuğu ve SEM görüntülerinden boyarmadde adsorpsiyonunda etkili olabilecek mikron boyutunda çok sayıda gözeneğin bulunduğu görülmüştür.

- MB adsorpsiyonunda kullanılan PPS için Langmuir izotermine uyumlu $\left(\mathrm{R}^{2}=0.999\right)$ ve qmax değeri $12.5 \mathrm{mg} / \mathrm{g}$ olarak belirlenmiştir. Kinetik değerlendirilmesinde ise birinci derece kinetik model geçerlidir.

- İyonik şiddetteki artış ile birlikte MB giderme verimlerinde artış görülmüştür. $2000 \mathrm{mg} / \mathrm{L} \mathrm{NaCl}$ uygulamasında $\% 91$ 'lik maksimum giderme verimi elde edilmiş, ancak $2500 \mathrm{mg} / \mathrm{L} \mathrm{NaCl}$ uygulaması ile maksimum giderme verimi bir miktar düşmüştür (\%87). Elde edilen sonuçlara göre iyonik şiddetin varlığ i ile adsorpsiyon genel olarak olumlu etkilendiğinden, bu durumun boyar maddenin ayrışmasından (dissosiasyonu) ileri geldiği söylenebilmektedir.

Sonuç olarak, tekstil endüstrisinde bol miktarda kullanılan MB boyarmaddesinin adsorpsiyon ile gideriminde, PPS kullanımı değerlendirilmiş olup, renk gideriminde ticari aktif karbona alternatif olarak kullanılabileceği belirlenmiştir. Ancak, PPS'nin qmax değerinin ticari aktif karbona kıyasla düşük olması sebebiyle, yüksek miktarda adsorban (PPS) kullanımı söz konusudur.

Ancak, PPS'ye uygulanabilecek çeşitli kimyasal aktivasyon yöntemleri ile qmax değerleri arttırılabilmekte olup, bu konuda daha fazla çalışma yapmaya gereksinim duyulmaktadır. Ticari aktif karbonun yerine kullanılacak PPS'nin atık materyalden üretilmiş olması ekonomik ve ekolojik açıdan uygulamayı avantajlı kılmaktadır.

\section{Kaynaklar}

Akçay T., (2014), Trakya bölgesinde çeltik sapının biyokütle potansiyeli ve enerji değerlerinin saptanması, Namık Kemal Üniversitesi, Fen Bilimleri Enstitüsü, Yüksek Lisans Tezi, Tekirdağ.

Aktaş T., Dalmış İ.S., Tuğ S., Dalmış F., Kayişoğlu B., (2017), Çeltik Saplarının Gazlaştırılması Amacıyla Laboratuvar Tipi Bir Gazlaştırıcının Geliştirilmesi ve Denenmesi, Tekirdağ Ziraat Fakültesi Dergisi, 14(02), 119-128.

Alaya M., Hourieh M., Youssef A., El-Sejarah F., (1999), Adsorption properties of activated carbons prepared from olive stones by chemical and physical activation, Adsorption Sci. Technol., 18, $27-42$.

Auta M., Hameed B.H., (2012), Modified Mesoporous Clay Adsorbent for Adsorption Isotherm and Kinetics of Methylene Blue, Chem. Eng. J., 198-199, 219-227.

Aydın H., Bulut Y., Yerlikaya C., (2008), Removal og Copper (II) from Aqueous Solution by Adsorption onto Low-Cost Adsorbents, J. Environ. Manage., 87, 37-45. 
Aygun A., Yenisoy-Karakas S., Duman I., (2003), Production of Granular Activated Carbon from Fruit Stones and Nutshells and Evaluation of Their Physical, Chemical and Adsorption Properties, Microporous Mesoporous Mater., 66, 189-195.

Ayoob S., Gupta A.K., Bhakat P.B., Bhat V.T., (2008), Investigations on the Kinetics and Mechanisms of Sorptive Removal of Fluoride from Water Using Alumina Cement Granules, Chem. Eng. J., 140, 6-14.

Cheng M., Zeng G., Huang D., Lai C., Liu Y., Zhang C., Wang R., Qin L., Xue W., Song B., Ye S., Yi H., (2018), High adsorption of methylene blue by salicylic acid-methanol modified steel converter slag and evaluation of its mechanism, Journal of Colloid and Interface Science, 515, 232-239.

Claoston N., Samsuri A.W., Ahmad Husni M.H., Mohd Amran M.S., (2014), Effects of pyrolysis temperature on the physicochemical properties of empty fruit bunch and rice husk biochars, Waste Management \& Research, 32(4), 331 -339.

Çaylak E., (2007), Ucuz adsorban kullanımıyla sulardan Cr(VI), fenol ve boyar maddelerin uzaklaştırlması, Ege Üniversitesi Fen Bilimleri Enstitüsü, Yüksek Lisans Tezi, İzmir.

Dahri M.K., Kooh M.R.R., Linda B.L., Lim L.B.L., (2014), Water Remediation Using Low Cost Adsorbent WalnutShell for Removal of Malachite Green: Equilibrium, Kinetics, Thermodynamic and Regeneration Studies, J. Environ. Chem. Eng., 2, $1434-1444$.

Demiral İ., Çemrek Kul Ş., (2014), Pyrolysis of apricot kernel shell in a fixed-bed reactor: Characterization of bio-oil and char, Journal of Analytical and Applied Pyrolysis, 107, 17-24.

Dincer A.R., Gunes Y., Karakaya N., Gunes E., (2007), Comparison of Activated Carbon and Bottom Ash for Removal of Reactive Dye from Aqueous Solution, Bioresour. Technol., 98, 834-839.

Elekçioğlu İ.H., Tülek A., (2009), Çeltik Beyaz Uç Nematodu (Aphelenchoides besseyi Christie pv.oryzae Aphelenchida: Aphelenchoidae), 1. Çeltik Sempozyumu, Tekirdağ, ss.39-48.

El-Halwany M.M., (2010), Study of adsorption isotherms and kinetic models for Methylene Blue adsorption on activated carbon developed from Egyptian rice hull (Part II), Desalination, 250(1), 208-213.

Foo K. Y., Hameed B. H., (2009), Utilization of rice husk ash as novel adsorbent: a judicious recycling of the colloidal agricultural waste, Advances in Colloid and Interface Science, 152(1-2), 39-47.

Gupta S.S., Bhattacharyya K., (2011), Kinetics of Adsorption of Metal Ions on Inorganic Materials: A review, Adv. Colloid Interface Sci., 162, 39-58.

Hameed B.H., El-Khaiary M.I., (2008), Kinetics and equilibrium studies of malachite green adsorption on rice straw-derived char, Journal of Hazardous Materials, 153, 701-708.

Hameed B.H., El-Khaiary M.I., (2008), Batch Removal of Malachite Green from Aqueous Solutions by Adsorption on Oil Palm Trunk Fibre: Equilibrium Isotherms and Kinetic Studies, Journal of Hazardous Materials, 154, 237-244.

Huang Y.H., Hsueh C.L., Cheng H.P., Su L.C., Chen C.Y., (2007), Thermodynamics and Kinetics of Adsorption of Cu(II) onto Waste Iron Oxide, J. Hazard. Mater., 144, 406-411.

Jain C.K., Kumar A., Izazy H., (2009), Color Removal from Paper Mill Effluent Through Adsorption Technology, Environ Monit Assess., 149, 343-348.

Kalderis D., Koutoulakis D., Paraskeva P., Diamadopoulos E., Otal E., Valle J. O., Fern' andez-Pereira C., (2008), Adsorption of polluting substances on activated carbons prepared from rice husk and sugarcane bagasse, Chemical Engineering Journal, 144 (1), 42-50.

Kaykığlu G., (2016), Kolemanit ve Üleksit Atı̆̆ ile Sulu Çözeltilerden Metilen Mavisi Giderimi: Kinetik ve İzoterm Değerlendirmesi, CBU J. of Sci., 12(3), 499-509.

Kaykioğlu G., Güneş, E., (2016) Kinetic and Equilibrium Study of Methylene Blue Adsorption Using H2SO4-activated Rice Husk Ash, Desalination and Water Treatment, 57, 7085-7097.

Li Y., Du Q., Liu T., Peng X., Wang J., Sun J., Wang Y., Wu S., Wang Z., Xia Y., Xia L., (2013), Comparative Study of Methylene Blue Dye Adsorption onto Activated Carbon, Graphene Oxide, and Carbon Nanotubes, Chemical Engineering Research and Design., 91, 361-368.

Li Y., Du Q., Liu T., Sun J., Wang Y., Wu S., Wang Z., Xia Y., Xia L., (2013), Methylene Blue Adsorption on Graphene Oxide/Calcium Alginate Composites, Carbohydrate Polymers., 95, 501- 507.

Mane V.S., Mall I.D.,Srivastava V.C., (2007), Kinetic and Equilibrium Isotherm Studies for the Adsorptive Removal ofBrilliant Green Dye from Aqueous Solution by Rice Husk Ash, J. Environ. Manage., 84, 390-400.

McKay G., Blair H., Gardiner J.R., (1989), The Adsorption of Dyes onto Chitin in Fixed Bed Column and Batch Adsorbers, J. Appl. Polym. Sci., 28, 1499-1544.

Mouni L., Belkhiri L., Bollinger J.-C., Bouzaza A., Assadi A., Tirri A., Dahmoune F., Madani K., Remini H., (2018), Removal of Methylene Blue from aqueous solutions by adsorption on Kaolin: Kinetic and equilibrium studies, Applied Clay Science, 153, 3845.

Naiya T.K., Bhattacharyaa A.K., Mandal S., Das S.K., (2009), The Sorption of Lead(II) Ions on Rice Husk Ash, J. Hazard. Mater., 163, $1254-1264$.

Panneerselvam P., Morad N., Tan K. A., (2011), Magnetic nanoparticle ( $\left.\mathrm{F}_{3} \mathrm{O}_{4}\right)$ impregnated onto teawaste for the removal of nickel(II) from aqueous solution, Journal of Hazardous Materials, 186(1), 160-168.

Salehi R., Arami M., Mahmoodi N. M., Bahrami H., Khorramfar S., (2010), Novel biocompatible composite (Chitosanzinc oxide nanoparticle): preparation, characterization and dye adsorption properties, Colloids and Surfaces B: Biointerfaces, 80(1), 8693.

Suman S., Gautam S., (2017), Pyrolysis of coconut husk biomass: Analysis of its biochar properties Energy Sources, Part A: Recovery, Utilization, and Environmental Effects, 39(8), 761-767.

Sürek H., Beşer N., Kaya R., (2007), Çeltikte Üstten Biçmenin Dane Verimi ve Bazı Agronomik Karakterlere Etkisi, Türkiye VII. Tarla Bitkileri Kongresi, 25-27 Haziran, Erzurum.

Xu R.K., Xiao S.C., Yuan J.-H., Zhao A.Z., (2011), Adsorption of methyl violet from aqueous solutions by the biochars derived from crop residues, Bioresour. Technol., 102 (22), 10293-10298.

Wang Y., Zeng L., Ren X., Song H., Wang A., (2010), Removal of Methyl Violet from aqueous solutions using poly (acrylic acid-coacrylamide)/attapulgite composite, Journal of Environmental Sciences, 22(1), 7-14. 
Wu Z., Zhong H., Yuan X., Wang H., Wang L., Chen X., Zeng G., Wu Y., (2014), Adsorptive removal of methylene blue by rhamnolipid-functionalized graphene oxide from Wastewater, Water Research, 67, 330-344.

Yang Y., Lin X., Wei B., Zhao Y., Wang J., (2013), Evaluation of adsorption potential of bamboo biochar for metal-complex dye: equilibrium, kinetics and artificial neural network modeling, Int. J. Environ. Sci. Technol., 11:1093-1100.

Zhang G., Sun Y., Shi Y., Jia Y., Xu Y., Zhao P., Zhang Y., (2016), Characteristic and kinetics of corn stalk pyrolysis in a high pressure reactor and steam gasification of its char, Journal of Analytical and Applied Pyrolysis, 122, 249-257. 